\title{
Effects of Exogenous Gamma-aminobutyric Acid on Absorption and Regulation of Ion in Wheat Under Salinity Stress
}

Xiaodong Wang ${ }^{1}$, Hongtu Dong ${ }^{1}$, Peichen $\mathrm{Hou}^{2}$, Hang Zhou ${ }^{1}$, Lulu He${ }^{1}$, Cheng Wang ${ }^{2(\mathbb{凶})}$.

\author{
${ }^{1}$ Department of Bio-Instruments, Beijing Research Center of Intelligent Equipment for Agriculture, Beijing, \\ Shugang Hua Yuan Middle Road No. 11, Haidian District, China \\ wangxdenercita.org.cn \\ ${ }^{2}$ Beijing Research Center for Information Technology in Agriculture, Beijing, Shugang Hua Yuan Middle Road
} No. 11, Haidian District, China

wangc@nercita.org.cn

\begin{abstract}
Gamma-aminobutyric acid (GABA), a four-carbon non-protein amino acid, is a significant component of the free amino acid pool, there are numerous reports that rapid and large increases in GABA levels occur in plants, in response to a variety of biotic and abiotic stress. Based on its metabolism and putative roles in plants, GABA is considered a natural chemical to increase wheat salt-tolerance. So this study investigated the exogenous GABA on wheat seedling (Triticum aestivum L. cv. Changwu134 and zhouyuan9369) growth and absorption of salt ions under normal or salt-stressed conditions. The results demonstrated that salt stress inhibited growth of wheat seedlings, decreased dry weight and water content, altered ion balance within the stressed seedlings. Pretreatment with $50 \mathrm{mg} / \mathrm{L}$ GABA increased seedling biomass and $\mathrm{K}^{+}$content in leaves, decreased $\mathrm{Na}^{+}$content in leaves and roots under salt-stressed conditions by improving $\mathrm{Na}^{+}$ exclusion, $\mathrm{K}^{+}$retention. These results indicated that exogenous $50 \mathrm{mg} / \mathrm{L}$ GABA improved seedling growth and alleviated the inhibition due to salt stress of wheat by altered ion balance. Exogenous GABA has the capability of restraining transportation of salt ions to leaves and sustaining normal function of leaves. And the effect of exogenous GABA is obvious in common variety (zhouyuan9369) than in salt-tolerance variety (changwu134).
\end{abstract}

Keywords: Gamma-aminobutyric acid (GABA), salinity stress, Wheat (Triticum aestivum L.), Ion flux, Ion balance.

\section{Introduction}

Salinity is one of the major environmental factors which limited plant growth and productivity, there is about $22 \%$ of the world's cultivated lands were influenced by salinity. ${ }^{[1,2]}$ Saline lands in China is approximately $4.88 \%$ of the total available lands, and $6.62 \%$ of the total agricultural lands have become salinization. ${ }^{[3]}$ The saline soils are increasing with the development of industry and the irrigation in agriculture. ${ }^{[4]}$ Therefore, improve the salt resistance of crops and 
the cultivation measures are the most important methods for the use of saline soils in future. ${ }^{[5]}$

There are lots of reports that several kinds of amino acids in plants under salt stress were increased, including proline, gamma-aminobutyric acid(GABA), and others. It has been proposed that free amino acids acted as osmolytes, which adjusted the osmosis. ${ }^{[6]}$ Another view is that free amino acids through regulatory or osmosis protective functions, and then adjusted the osmosis in the plant. ${ }^{[7]}$ Gamma-aminobutyric acid is one of the free amino acids in most organisms, which is a four-carbon non-protein amino acid and it plays very important role in organism. ${ }^{[8]}$ There are numerous reports that rapid and large increases in GABA levels occur in plants, in response to a variety of biotic and abiotic stress, such as flooding, drought, cold, heat, hypoxia, UV radiation, pest, mechanical stimulation and damage. ${ }^{[9,10,11,12]}$ GABA synthesis shows a relationship with plant defense and plant growth and development under stresses ${ }^{[8,13]}$. The interaction between GABA and other stress-related phytohormones like abcisic acid and ethylene were also noted ${ }^{[14,15,16]}$. Recently roles for GABA as an intra-, inter-cellular and long-distance signaling molecule ${ }^{[17,18]}$, and an endogenous growth regulator ${ }^{[15,19]}$ in plants were suggested. Low concentration of GABA promotes growth but high level inhibits the growth of Stellaria ${ }^{[15]}$.

There is some report on the effect of exogenous GABA on crop growth under abiotic stress conditions, which is essential to its possible agronomic application. Exogenous GABA application could promote the ROS metabolism and keep the stability of cell membrane, to enhance the tolerance of melon to salinity-alkalinity stress ${ }^{[20]}$. The resistance to root hypoxia short-term can be enhanced by the exogenous GABA on a sensitive genotype of Prunus ${ }^{[21]}$. Furthermore some reports show that exogenous Gamma-aminobutyric acid (GABA) ameliorated $\mathrm{NaCl}$-induces $\mathrm{K}^{+}$efflux from barley roots rapidly ${ }^{[22,23]}$.

Based on its metabolism and putative roles in plants, GABA is considered a natural chemical to increase wheat thermo-tolerance. However, the effects of GABA on salt-resistance and ion transport under salt stress still need more experimental tests. We investigated the effects of GABA on seedling growth, accumulation of salt ions and the ion fluxes of $\mathrm{Na}^{+}$and $\mathrm{K}^{+}$on the response to salt stress in wheat, to explore the potential for its application to enhance the resistance of wheat to salt stress.

\section{Materials and methods}

\subsection{Plant materials and treatment}

The experimental wheat materials were: Changwu134 (the salt tolerant one from Shanxi, china); Zhouyuan9369 (the high-yield one from Shandong Laizhou, china).

Seeds were surface disinfected with $5 \% \mathrm{NaClO}$ for $6 \mathrm{~min}$, then soaked in sterile water for $12 \mathrm{~h}$. Each culture dishes put 50 seeds, lined with one layer of filter paper and wet with $20 \mathrm{ml}$ treatment solutions: $1 / 2$ Hoagland. Seeds were germinated in the dark with suitable germination temperature $25^{\circ} \mathrm{C}$, and changed the filter paper every 2 days. After 6 days, the young seedlings were about $6 \mathrm{~cm}$ height, then transferred these seedlings to plastic pots filled with $1 / 2$ Hoagland solution, which grow on foam 
boards (with same size holes). When the seedlings were $10 \mathrm{~cm}$, the half of seedlings were treated with $50 \mathrm{mg} \cdot \mathrm{L}^{-1}$ GABA solution (prepared with $1 / 2$ Hoagland solution) and the control (1/2 Hoagland solution) for 24 hours. After that, a half of the above seedlings were transfer to $150 \mathrm{mM} \mathrm{NaCl}$ solution. So the treatments in this experiment were $\mathrm{CK}, \mathrm{GABA}, \mathrm{CK}+\mathrm{NaCl}$, and $\mathrm{GABA}+\mathrm{NaCl}$. All the solutions were replaced every 2 days. Seedlings were grown in a growth chamber at day/night cycle of 14/10 hours and normal temperature day/night was $25 / 20^{\circ} \mathrm{C}$. Flux measurement of $\mathrm{Na}^{+}$and $\mathrm{K}^{+}$ were detected at $1 \mathrm{~h}$ and $24 \mathrm{~h}$ salt stress. After the salt stress, morphological characteristic, water content of plants were measured, leaves and roots were sampled from the each treatment plants of the six wheat materials and used for content analysis of $\mathrm{Na}^{+}$and $\mathrm{K}^{+}$.

\subsection{Analysis of $\mathrm{Na}^{+}$and $\mathrm{K}^{+}$}

The extraction and measurement of $\mathrm{Na}^{+}$and $\mathrm{K}^{+}$in leaves and roots were tested according to Wang and Zhao with slight modifications. ${ }^{[24]}$ Ten milliliters of $\mathrm{dH}_{2} \mathrm{O}$ was added to the dried plant powder(each with $50 \mathrm{mg}$ ) and boiled for $2 \mathrm{~h}$, then added $\mathrm{dH}_{2} \mathrm{O}$ to make a final volume of $50 \mathrm{ml}$. After filtered, the $\mathrm{Na}^{+}$and $\mathrm{K}^{+}$content were assayed by the Atomic Absorption Spectrometry.

\subsection{Measurements of net $\mathrm{K}^{+}$and $\mathrm{Na}^{+}$fluxes with SIET}

$\mathrm{K}^{+}$and $\mathrm{Na}^{+}$net fluxes were non-invasively measured by using the scanning ion-selective electrode technique (SIET) (the SIET system is plants dynamic ion fluxes detection device, AI-IFDD-I; Beijing Research Center for Information Technology in Agriculture; Ma R et al. 2017) ${ }^{[25]}$. The methods were slightly modified as described in Ma $\mathrm{R}$ et al. (2017). In this experiment, we used the ion-selective microelectrode to measure the aim ions concentration gradients, which closed to the root and moved between two points in a stated distance of 30 $\mu \mathrm{m}$. The time constant of the liquid ion exchange (LIX) electrodes and the mechanical distance of gradient are the main factors for stability of measurement. The SIET results can be as low as picomolar levels, the premise is each point need 1 to 2 seconds to measured, so every reciprocating process need about $3.3 \mathrm{~s}$. The predefined sampling routine handled electrode move from one set to another, meanwhile moved by the three-dimensional micro stepper motor manipulator. The microelectrode ( $\Phi 4.5 \pm 0.5 \mu \mathrm{m}, \mathrm{XY}-\mathrm{CGQ}-01$; Xuyue (Beijing) Sci. and Tech. Co., Ltd., Beijing, China) was filled with a backfilling solution about $1 \mathrm{~cm}$, the backfilling solution for $\mathrm{Na}^{+}$is $100 \mathrm{mM} \mathrm{NaCl}, \mathrm{K}^{+}$is $100 \mathrm{mM} \mathrm{KCl}$. Then the microelectrode front were filled with $15-20 \mu \mathrm{m}$ of $\mathrm{Na}^{+}$(XY-SJ-Na; YoungerUSA) selective liquid ion-exchange cocktails (LIX) and 180-190 $\mu \mathrm{m}$ for $\mathrm{K}^{+}$(XY-SJ-K; YoungerUSA). Inserted the $\mathrm{Ag} / \mathrm{AgCl}$ wire electrode holder (YG003-Y11; YoungerUSA) in the back of the electrode, and make sure the $\mathrm{Ag} / \mathrm{AgCl}$ wire contact with the electrolyte solution in the electrode. For the accuracy of the experiment, using the calibrator verify the ion-selective electrodes by the calibration solution: (i) $\mathrm{Na}^{+}: 0.5,5 \mathrm{mM} \mathrm{NaCl}\left(\mathrm{Na}^{+}\right.$ concentration in the measuring buffer was $0.9 \mathrm{~mm}$ ); (ii) $\mathrm{K}^{+}: 0.1,1 \mathrm{mM} \mathrm{KCl}\left(\mathrm{K}^{+}\right.$ 
concentration in the measuring buffer was $0.1 \mathrm{~mm}$ ). The Nernst slopes of electrodes was $58 \pm 6 \mathrm{mV} /$ decade could be used in our study, and the result were convert by Fick's law of diffusion into ion flux.The data and images acquisition, motion control were completed with the plants dynamic ion fluxes detection device's operational software.

\section{Results}

\subsection{Effects of exogenous GABA on growth of wheat seedlings and roots under salt} stress
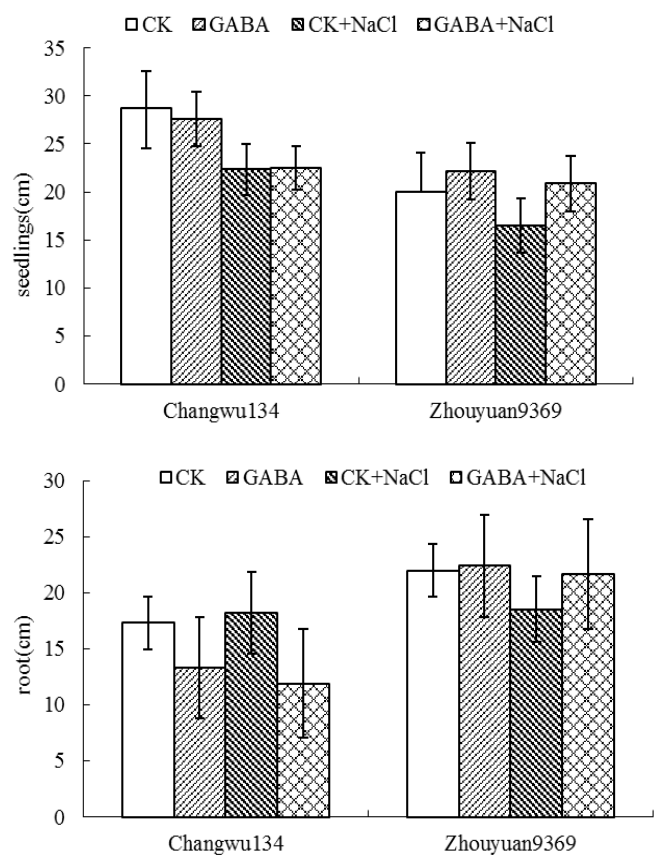

Fig.1. Effect of GABA on seedling height and root length under normal conditions and salinity stress 2 days about two wheat cultivars: salt-tolerant (Changwu134) and high-yield

(Zhouyuan9369)

$24 \mathrm{~h}$ of salinity treatment affect the growth on shoot and root, with both stem and root length obviously reduced. However, the influence of salinity is different between wheat cultivars. For seedling height, compared with the control, the seedling length of Changwu134 was significantly lower after the salt treatment, and there was no difference between GABA treatment and CK after stress. For zhouyuan9369, NaCl inhibited the growth of control, and there was no significant change under GABA treatment. For root length, GABA suppresses growth of Changwu134, under CK and salt stress conditions. In contrast, the application of GABA reduced the effect of salt stress for root.

3.2 Effects of GABA on accumulation of dry matter in wheat and water content in leaves under normal conditions and salinity stress 

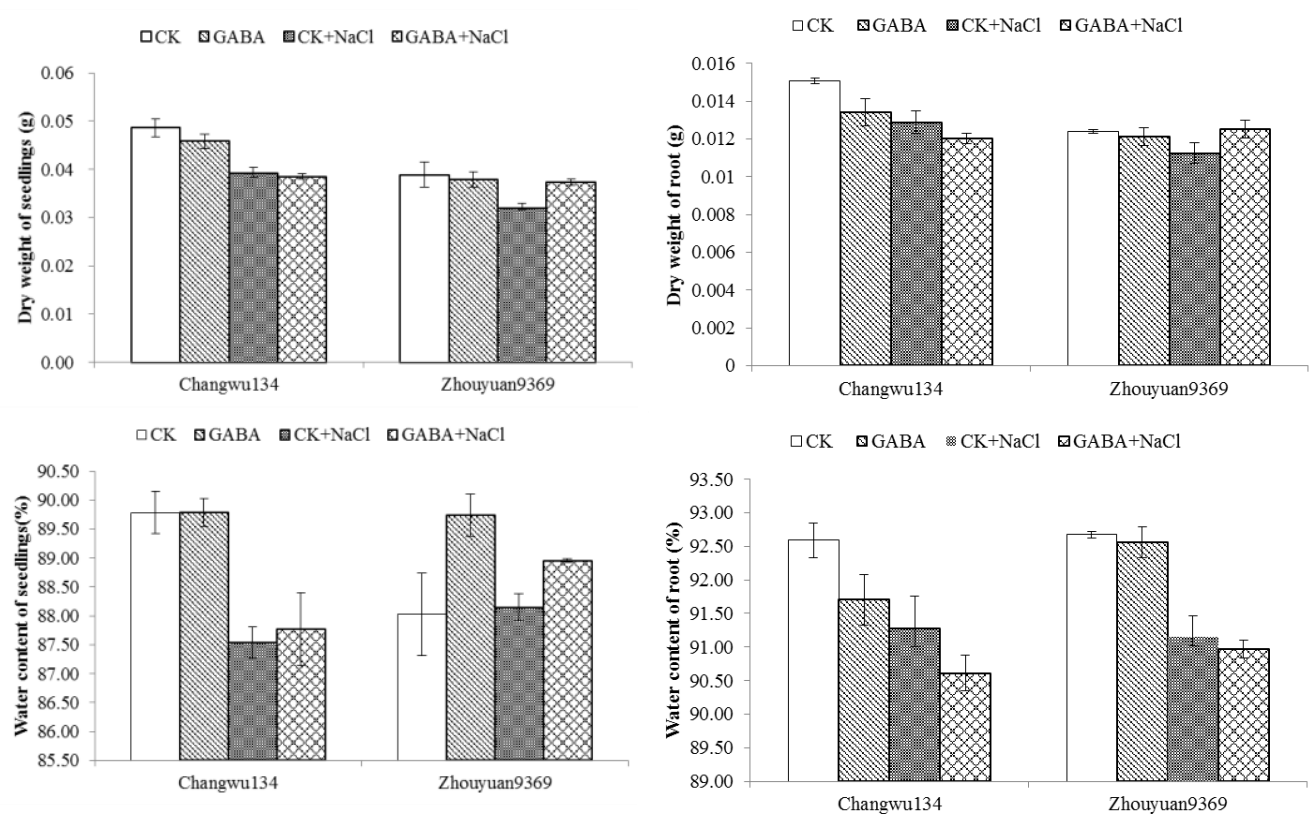

Fig.2. Effect of GABA on dry weight and water contain under normal conditions and salinity stress 2 days about two wheat cultivars: salt-tolerant (Changwu134) and high-yield

(Zhouyuan9369)

The growth of the two varieties of seedlings has been significantly inhibited by the treatment of $150 \mathrm{mM} \mathrm{NaCl}$. Meanwhile, we identify the dry weight, water contain of the steam and the root have been reduced significantly.

The effects of GABA on the growth of wheat seedlings under salt stress were different due to cultivars. Pretreatment with $50 \mathrm{mg} / \mathrm{L}$ GABA increased stem dry weight, root dry weight and water content of stem for Zhouyuan9369. Changwu134, on the contrary, through GABA treatment, the water content of root become greater sensitivity under salt stress.

3.3 Exogenous GABA changes in content of $\mathrm{K}^{+}$and $\mathrm{Na}^{+}$in roots and leaves of changwu134, zhouyuan936 and Chinese-spring under salinity stress

In the $150 \mathrm{mM} \mathrm{NaCl}$ stress, $\mathrm{K}^{+}$concentrations were reduced in root of Changwu134, but there were no differences in stem $\mathrm{K}^{+}$content. Meanwhile the effect of salt stress on $\mathrm{K}^{+}$accumulation was significant fall off both in stem and root of Zhouyuan9369.

After pretreatment with $50 \mathrm{mg} / \mathrm{L}$ GABA, compared with $\mathrm{NaCl}$ treatment, $\mathrm{NaCl}^{+}$ GABA treatment had no significant change the content of $\mathrm{K}^{+}$, except in leaves of Zhouyuan9369 were increased. 
$\square \mathrm{CK} \quad \mathrm{GABA} \mathrm{CK}+\mathrm{NaCl} \square \mathrm{GABA}+\mathrm{NaCl}$

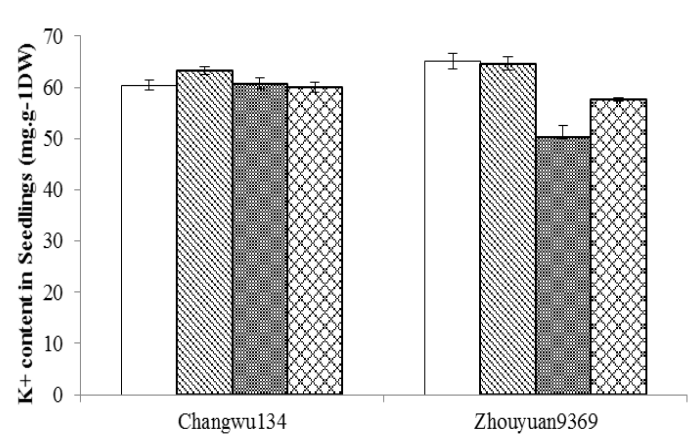

$\square \mathrm{CK} \quad \square \mathrm{GABA} \square \mathrm{CK}+\mathrm{NaCl} \quad \mathrm{GABA}+\mathrm{NaCl}$

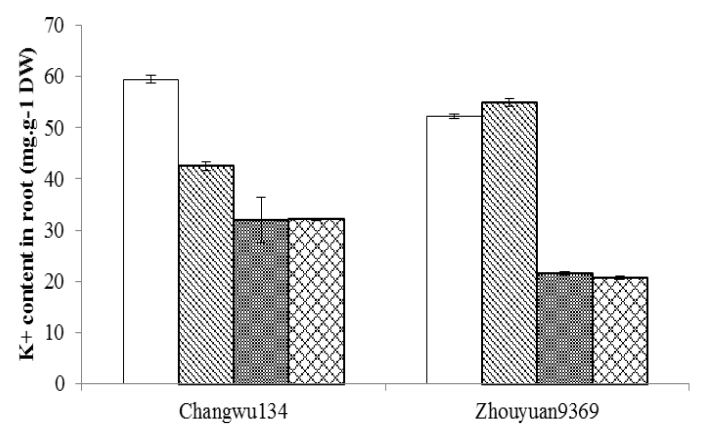

Fig.3.The accumulation of $\mathrm{K}^{+}$in the different organization of wheat under salt stress

Same as the most of research, salt stress caused dramatic increase in both stem and root $\mathrm{Na}^{+}$content. After $150 \mathrm{mM} \mathrm{NaCl}$ treat $24 \mathrm{~h}$, Changwu134 and Zhouyuan9369 were several fold increase in $\mathrm{Na}^{+}$accumulation. It's worth noting that GABA greatly alleviated the effect of the accumulation of $\mathrm{Na}^{+}$caused by $\mathrm{NaCl}$ stress on plants, especially on salt sensitive cultivar zhouyuan9369, both in the shoot and root, however, in the root of Changwu134, have no evident changes.

$\square \mathrm{CK}$ @ $\mathrm{GABA} \quad \mathrm{MCK}+\mathrm{NaCl} \quad \mathrm{G} \mathrm{GABA}+\mathrm{NaCl}$

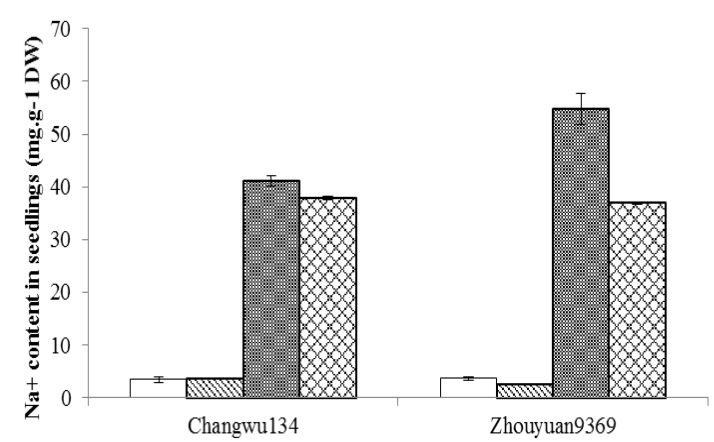

$\square \mathrm{CK} \quad \mathrm{G} \mathrm{GABA} \quad \mathrm{CK}+\mathrm{NaCl} \quad \square \mathrm{GABA}+\mathrm{NaCl}$

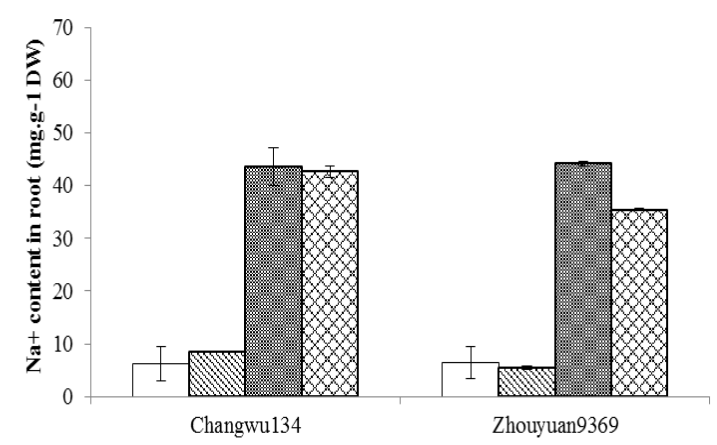

Fig.4. The accumulation of $\mathrm{Na}^{+}$in the different organization of wheat under salt stress

\subsection{Effects of exogenous GABA on $\mathrm{K}^{+}$fluxes in roots of changwu134, zhouyuan9369 and Chinese-spring under salinity stress}

To study the effect of GABA on $\mathrm{K}^{+}$fluxes of Changwu134 and Zhouyuan9369 under the condition of salt stress. The non-invasive ion-selective microelectrode SIET technique was used to discover absorption of root $\mathrm{K}^{+}$meiosis region in two kinds of wheat cultivars with the normal growth, $1 \mathrm{~h}$-salt stress and $24 \mathrm{~h}$-salt stress condition.

According to the detection results, it is found that $\mathrm{K}^{+}$efflux of $\mathrm{CK}$ in salt-resistant variety Changwu134 was faster than that of wheat material processed by GABA under normal condition. With $1 \mathrm{~h}$-salt stress, $\mathrm{K}^{+}$efflux increases, while there is no obvious difference between $\mathrm{K}^{+}$efflux of wheat material processed by GABA and CK. After $24 \mathrm{~h}$ salt stress, $\mathrm{K}^{+}$efflux decreases and the distinction between them is still not obvious. $\mathrm{K}^{+}$efflux of $\mathrm{CK}$ in salt-sensitive variety Zhouyuan9369 is a bit faster than that treated by GABA under normal condition. After $1 \mathrm{~h}$ of salt stress, $\mathrm{CK}$ and GABA treated efflux were both decreased, meanwhile, the treatment with GABA was 
become a little influx. After $24 \mathrm{~h}$ stress, $\mathrm{K}^{+}$efflux increased, and $\mathrm{CK}$ flux was significantly higher than GABA treated.
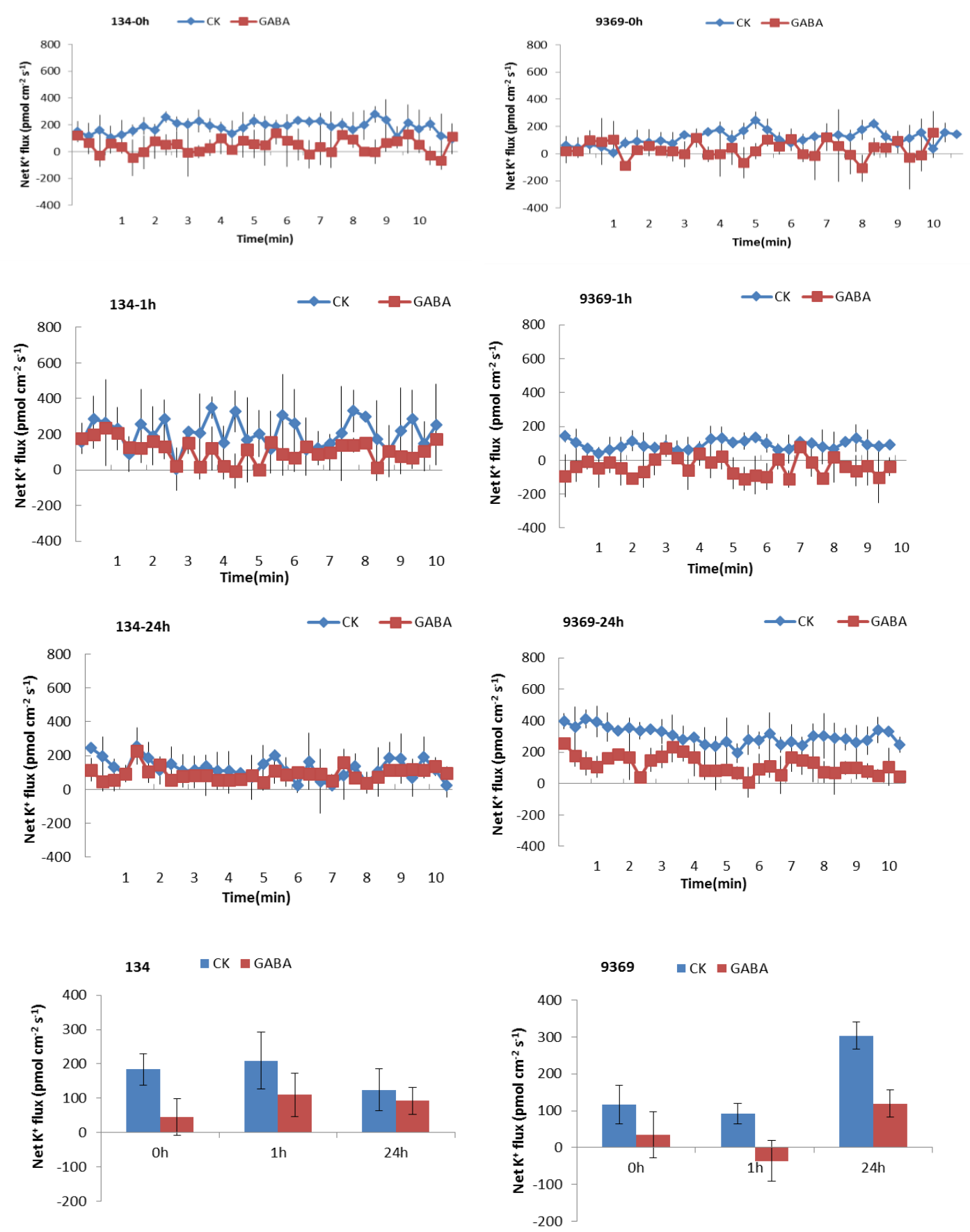

Fig.5. $\mathrm{K}^{+}$fluxes measured from mature zone (10 mm from root tip) of two wheat cultivars in response to $150 \mathrm{mM} \mathrm{NaCl}$ treatments $\left(0 \mathrm{~h}, 1 \mathrm{~h}, 24 \mathrm{~h}\right.$ ) (““+”response $\mathrm{K}^{+}$efflux; ““-"response $\mathrm{K}^{+}$influx)

\subsection{Effects of exogenous GABA on $\mathrm{Na}^{+}$fluxes in roots of changwu134,} zhouyuan9369 and Chinese-spring under salinity stress

Ion fluxes data revealed that the $\mathrm{Na}^{+}$flux at the root changed obviously after $1 \mathrm{~h}$ $\mathrm{NaCl}$ stress. There was a little influx of $\mathrm{Na}^{+}$into the control seedlings, while the GABA pretreatment one had a higher efflux for Zhouyuan9369. For Changwu134, there was no significant difference in $\mathrm{Na}^{+}$efflux between $\mathrm{CK}$ and GABA treatment 
compare with the control under non-stressed conditions.

After 24 hours stress, the CK of salt tolerant wheat materials changwu134 $\mathrm{Na}^{+}$ efflux sharply reduced, while the GABA treatment remain the same as $1 \mathrm{~h}$ salt stress. On the contrary, CK and GABA treat of zhouyuan9369 showed efflux largely, and GABA treated one showed efflux rate greater than CK.
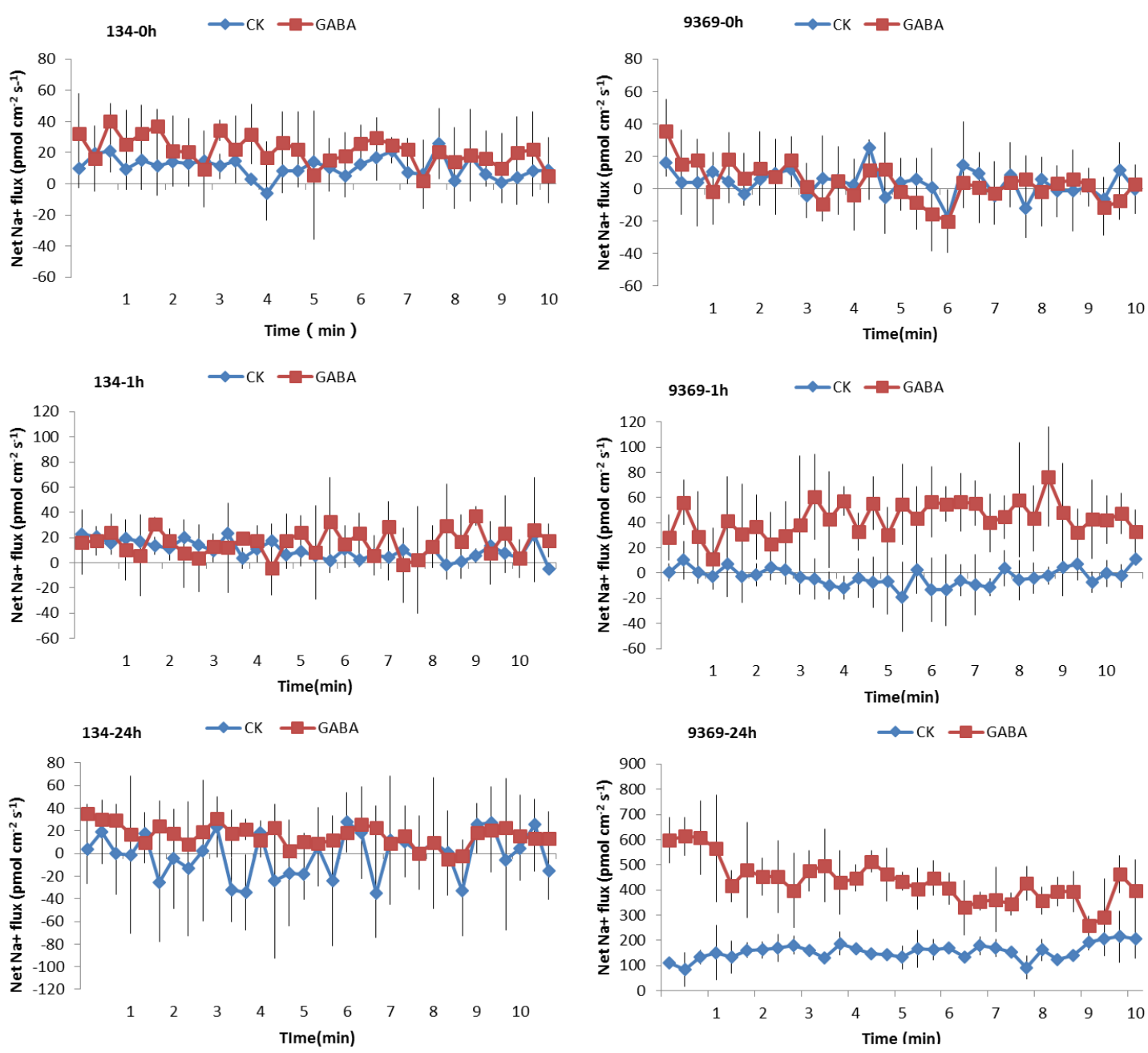

134

$\because \mathrm{CK}=\mathrm{GABA}$

9369

$\because \mathrm{CK} \backsim \mathrm{GABA}$
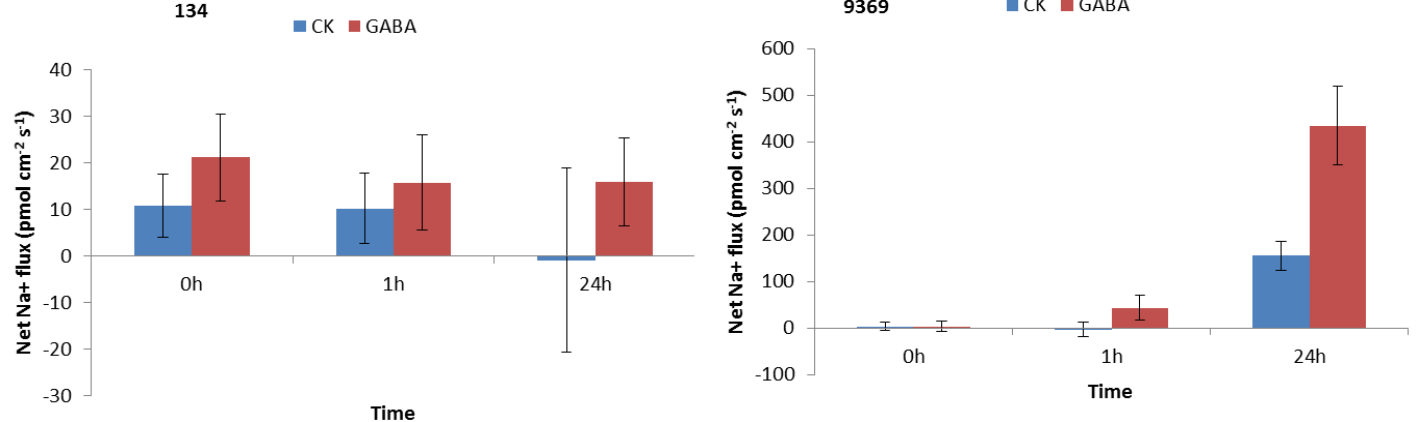

Fig.6. $\mathrm{Na}^{+}$fluxes measured from mature zone (10 mm from root tip) of two wheat cultivars in response to $150 \mathrm{mM}$

$\mathrm{NaCl}$ treatments (0h,1h,24h) (“+”"response $\mathrm{Na}^{+}$efflux; ““-"response $\mathrm{Na}^{+}$influx)

\section{Discussion}

The influence of salt stress on growth were investigated as plant height and dry weight differences in changwu134 and zhouyuan9369 plants. In this study, plant compared with the control, big difference was observed between GABA and 
non-GABA treatments. The salt stress treatment induced an obvious decrease in the growths and weights of the seedlings and root. The application of GABA alleviated the inhibition in seedling growth under salt stress, dry weights and water content of plant, Especially, zhouyuan9369 was enhanced remarkably, which similar to the results of Kathiresan $(1998)^{[15]}$. In his work, with increasing in GABA concentration in the culture, the stem length was increased, until a concentration of $250 \mu \mathrm{M}$ was reached. It is know that GABA treatment enhanced their endogenous GABA levels over control plants ${ }^{[15,26]}$. Which indicated that endogenous GABA accumulation could be influence the stem elongation and the accumulation of dry mass.

According to the reports that when plant root subjected to salt stress,

electrochemical gradient was established get through the plant membrane, and the ion homeostasis was disrupted by change of transported and accumulated of salt ions, and then the plant was injury ${ }^{[27,28,29]}$. In order to obtain a clear study of the GABA mechanisms essential, we focused only on the ion homeostasis in our work, to identify the effects of GABA to salt stress in wheat seedlings. In this study, a prominent $\mathrm{K}^{+}$ efflux was observed in root after $1 \mathrm{~h}$ and $24 \mathrm{~h}$ of salinity treatment (Fig.5), as reported by for rice ${ }^{[30]}$ and broad bean ${ }^{[31]}$. Meanwhile, wheat roots excluded $\mathrm{Na}^{+}$mightily after $1 \mathrm{~h}$ and $24 \mathrm{~h}$ of salt stress (Fig.6), which consistent with most of reports by Sun and others (2010) for P.euphrativa ${ }^{[32]}$, Cuin and others (2011) for wheat ${ }^{[33]}$, and Xie (2015) for cotton ${ }^{[34]}$. As same as changes of $\mathrm{K}^{+}$flux, the content of $\mathrm{K}^{+}$in seedlings and root after $24 \mathrm{~h}$ stressed reduced by $21 \%-58 \%$ compared with that in the CK (Fig3). Although wheat roots excluded $\mathrm{Na}^{+}$after $1 \mathrm{~h}$ of salt stress, and to become stronger after $24 \mathrm{~h}$ of salt stress, but $\mathrm{Na}^{+}$accumulation in seedlings and root under salt treatment increased by 6.94-14.75 fold compared with the normal treatment after $24 \mathrm{~h}$ salt stress (Fig4). However, pretreatment with GABA further increased the $\mathrm{Na}^{+}$efflux, and decreased $\mathrm{K}^{+}$efflux compared with that of non-GABA treated seedlings under $150 \mathrm{mM} \mathrm{NaCl}$ stress. Therefore, compared with the non-GABA treated, the $\mathrm{Na}^{+}$ content in the seedlings after $24 \mathrm{~h}$ stressed was remarkably decreased, whereas the $\mathrm{K}^{+}$ content was obviously increased in the seedlings. This result suggested that the uptake of $\mathrm{Na}^{+}$can be limited by wheat seedling under short-time $\mathrm{NaCl}$ stress conditions. But the root had to absorb $\mathrm{Na}^{+}$and accumulated in leaves, when the salt stress prolong to 24h (Fig.4). So the $\mathrm{Na}^{+} / \mathrm{K}^{+}$ratio in salt-stressed seedlings was increased. The salt tolerance plant depends on maintain a low $\mathrm{Na}^{+} / \mathrm{K}^{+}$ratio in the cytoplasm, via to regulated the ion-selective of absorption and transport ${ }^{[35]}$. GABA decreased the $\mathrm{Na}^{+}$ accumulation and increased the $\mathrm{K}^{+}$contents, especially in zhouyuan9369 which is not a salt-tolerant variety; therefore, the $\mathrm{Na}^{+} / \mathrm{K}^{+}$ratio was decreased. Accordingly, we hypothesize that exogenous GABA improved the seedling salt-tolerance by regulating the ion channels with high selectivity for $\mathrm{K}^{+}$over $\mathrm{Na}^{+}$to maintain a modest accumulation of $\mathrm{Na}^{+}$in the seedlings and to maintain a high $\mathrm{K}^{+} / \mathrm{Na}^{+}$ratio.

\section{Conclusion}

In conclusion, our results showed that GABA improved seedling growth and alleviated the inhibition due to salt stress of wheat by altered ion balance, especially to the common variety (zhouyuan9369). Exogenous GABA can restrained transportation of salt ions to leaves and sustained normal function of leaves. But the role of GABA in plant under salt stress need make further study.

\section{Acknowledgements}

The authors are thankful for the funding from the National Natural Science Foundation of China (61571443), and Scientific and Technological Innovation Team of Beijing Academy of Agricultural and Forestry Sciences (JNKYT201604).

\section{References}

1. Bhatnagar-Mathur, P., V. Vadez, K. K. Sharma.: Transgenic approaches for abiotic stress tolerance in plants:retrospect and prospects. In Plant Cell Rep. 27, 411-424(2008)

2. Munns, R., M. Tester.: Mechanisms of salinity tolerance. In: Annu. Rev. Plant Biol. 59, 651-681 (2008)

3. Yang, J.: Development and prospect of the research on salt-affected soils in China. In: Pedol. Sin. 45, 837-845(2008) (in Chinese)

4. Lobell D B, Ortiz-Monsterio J I, Gurrola F C, Valenzuela L.: Dentification of saline soils with multiyear remote sensing of crop yields. In Soil Sci Soc Am. 71, 777-783 (2007) 
5. Flowers, F.J. Improving crop salt tolerance.In: Journal of Experimental Botany 55, 307-319(2004)

6. Ford CW. Accumulation of low molecular weight solutes in water-stressed tropical legumes. In: Phytochem. 23, 1007-1015 (1984)

7. Wang H, Miyazaki S, Kawai K, Deyholos M, Galbraith DW, Bohnert HJ. Temporal progression of gene expression responses to salt shock in maize roots. In: Plant Mol Biol. 52, 873-891(2003)

8. Shelp B.J., Bown A.W., McLean M. D. Metabolism and functions of gamma-aminobutyric acid. In: Trend in Plant Sci. 4(11), 446-452(1999)

9. Satyanarayan V., Nair P.M.. Metabolism, enzymology and possible roles of 4-aminobutyrate in higher plants. In: Phytochem. 29, 367-375(1990)

10. Serraj R, Shelp B. J.,Sinclair T. R. Accumulation of $\gamma$-amniobutyric acid in nodulated soybean in response to drought stress. In: Physiol. Plant.102, 79-86 (1998)

11. Shelp B. J., Cauwenberghe O.R.V., Bown A. W. Gamma aminobutyrate: from intellectual curiosity to practical pest control. In: Can. J. Bot. 81, 1045-1048(2003)

12. Koppitz H., Dewender M., Ostendorp W., Schmieder K. Amino acid as indicators of physiological stress in common reed Phragmites australis affected by an extra flood. In Aquatic Bot. 79, 277-294 (2004)

13. Bown A.W., Zhang G.J. Mechanical stimulation 4-aminobutyric acid (GABA) synthesis and growth inhibition in soybean hypocotyls tissue. In: Can. J. Bot. 78, 119-123 (2000)

14. Kathiresan A. Gama-aminobutyric stimulates ethylene biosynthesis in sunflower. In: Plant Physiol. 115(1), 129-135(1997)

15. Kathiresan A. $\gamma$-aminobutyric acid promoted stem elongation in Stellaria longipes: the role of ethylene. In: Plant Growth Regul. 26, 131-137(1998)

16. Talannova V.V., Akimova T.V., Titov A.F. Effects of whole plant and local heating on the ABA content in cucumber seedling leaves and roots and on their heat tolerance. In: Plant Physiol. 50, 90-94(2003)

17. Bouche N., Lacombe B., Fromm H. GABA signaling: a conserved and ubiquitous mechanism. In: Trends in Cell Biol. 13(12), 607-610(2003)

18. Beuve N., Rispail, Laine P., Clquet, Ourry A., Deunff E.L. Putative role of $\gamma$-aminobutyric acid (GABA) as a long-distance signal in up-regulation of nitrate uptake in Brassica napus L. In: Plant Cell Environ. 27,1035-1046(2004)

19. Palanivelu R., Brass L., Edlund A.F., Preuss D. Pollen tube growth and guidance is regulated by $P O P 2$, an Arabidopsis gene that control GABA levels. In: Cell. 114, 47-59 (2003)

20. Xiang Li-xia, Hu Li-pan, Hu Xiao-hui, PAN Xiong-bo, REN Wen-qi. Response of reactive oxygen metabolism in melon chloroplasts to short-term salinity-alkalinity stress regulated by exogenous $\gamma$-aminobutyric acid. In: Chinese Journal of Applied Ecology. 26(12), 3746-3752(2015) (in Chinese)

21. Ariel Salvatierra, Paula Pimentel, Rubén Almada, Patricio Hinrichsen. Exogenous GABA application transiently improves the tolerance to root hypoxia on a sensitive genotype of Prunus rootstock. In: Environmental and Experimental Botany. 125, 52-66 (2016)

22. Cuin TA, Shabala S. Exogenously supplied compatible solutes rapidly ameliorate $\mathrm{NaCl}$-induced potassium eZux from barley roots. In: Plant Cell Physiol. 46, 1924-1933(2005)

23. Tracey Ann Cuin, Sergey Shabala. Amino acids regulate salinity- induced potassium efflux in barley root epidermis. In: Planta. 225,753-761(2007)

24. Wang B S, Zhao K F. Comparison of extractive methods of $\mathrm{Na}^{+}$and $\mathrm{K}^{+}$in wheat leave. In Plant Physiology Communications. 31(1), 50-52(1995) (In Chinese) .

25. Ma R, Wang C, Ma Q, Hou P C, Wang X D. Ion response of sunflower at sprouting stage to mixed salt stress [J]. Chinese Journal of Eco-Agriculture, 25(5):720-729(2017) (In Chinese).

26. M.S. Aghdam. Impact of exogenous GABA treatments on endogenous GABA metabolism in anthurium cut flowers in response to postharvest chilling temperature. In: Plant Physiology and Biochemistry. 106, 11-15(2016)

27. Zhu JK. Salt and drought stress signal transduction in plants. In: Annual Rev Plant Biol. 53, 247-273(2002)

28. Sun J, Chen SL, Dai SX, Wang RG, Li NY, Shen X, Zhou XY, Lu CF, Zheng XJ, Hu ZM, Zhang ZK, Song J, Xu [28] Y. NaCl-induced alternations of cellular and tissue ion fluxes in roots of salt-resistant and salt-sensitive poplar species. In: Plant Physiol. 149, 1141-1153(2009)

29. Silva P, Facanha AR, Tavares RM, Geros H. Role of tonoplast proton pumps and $\mathrm{Na}^{+} / \mathrm{H}^{+}$ antiport system in salt tolerance of Populus euphratica oliv. In: Plant Growth Regul. 29, 23-34 (2010)

30. Coskun D, Britto DT, Jean YK, Kabir I, Tolay I, Torun AA, Kronzucker HJ. K ${ }^{+}$efflux and retention in response to $\mathrm{NaCl}$ stress do not predict salt tolerance in contrasting genotypes of rice (Oryza sativa L.). In: PLOS ONE. 8, 1-16(2013) 
31. Percey WJ, Shabala L, Breadmore MC, Guijt RM, Bose J, Shabala S. Ion transport in broad bean leaf mesophyll under saline conditions. In: Planta. 240, 729-743(2014)

32. Sun J, Wang MJ, Ding MQ, Deng SR, Liu MQ, Lu CF, Zhuo XY, Shen X, Zheng XJ, Zhang ZK, Song J, Hu ZM, [32] Xu Y, Chen SL. $\mathrm{H}_{2} \mathrm{O}_{2}$ and cytosolic $\mathrm{Ca}^{2+}$ signals triggered by the PM $\mathrm{H}^{+}$-coupled transport system mediate $\mathrm{K}^{+} / \mathrm{Na}^{+}$homeostasis in NaCl-stressed Populus euphratica cells. In: Plant Cell Environ. 33, 943-958(2010)

33. Cuin TA, Bose J, Stefano G, Jha D, Tester M, Mancuso S, Shabala S. Assessing the role of root plasma membrane and tonoplast $\mathrm{Na}^{+} / \mathrm{H}^{+}$exchangers in salinity tolerance in wheat: in planta quantification methods. In: Plant Cell Environ. 34, 947-961(2011)

34. ZhiXia Xie, LiuSheng Duan, ZhaoHu Li, XiaoDong Wang, Xiaojing Liu. Dose-Dependent Effects of Coronatine on Cotton Seedling Growth Under Salt Stress. In: Journal of Plant Growth Regulation. 34,651-664(2015)

35. Ashraf M. Salt tolerance of cotton: some new advances. In: Crit Rev Plant Sci. 21, $1-30(2002)$ 